\title{
Effect of passage meditation program on nurses' level of hope and resilience who caring for patients with COVID 19
}

\author{
Samer Mabrook Abdelsalam Elnehrawy ${ }^{1}$, Marwa Abdelfatah Ahmed Zewiel ${ }^{2}$ \\ ${ }^{1,2}$ Lecturerof Psychiatric and Mental Health Nursing, Faculty of Nursing, Tanta \\ University
}

\begin{abstract}
Background: COVID-19 is an acute resolved disease but it can also be deadly, with a $2 \%$ case fatality rate. Health care workers are the frontline soldiers against COVID-19. They experienced fear, high level of stress, fatigue, grief and anxiety during facing pandemic. So, development and application of a meditative program that consistent with our culture can be valuable to control and overcome stress, building resilience and hope. Aim: To evaluate the effect of passage meditation program on nurses' level of hope and resilience who working with COVID 19 patients. Subjects and method: Study Design: A quasi-experimental, pre- post-test design was utilized in the current study. The study was conducted at Tanta chest hospital affiliated to Ministry of health. It was an online study through using Google forms (Google drive). Subjects: All of nurses (fifty nurses) working at Tanta chest hospital. Tools: two tools were used to gather data for this research, Hearth hope scale and the brief resilience scale (BRS). Method: a WhatsApp group were introduced for all nurses, the studied nurses were divided into five subgroups; each subgroup encompassed 10 nurses. Each subgroup was attending a total of 6 sessions. These sessions were scheduled as 3 sessions per week for duration of 2 weeks. Each session was lasted for about an hour. Results: there is a positive statistically significant relationship between the nurse total resilience score and hope score. Conclusion: the passage meditation program was effective in elevation hope level and improving resilience among nurses Recommendation: the current study suggested, the global nursing organizations work on drafting effective and proactive nurses' human-factor guidelines and network that embeds human factor as a dynamic shock absorber.
\end{abstract}

Key words: Passage meditation, hope, resilience, COVID 19. 


\section{Introduction}

Since late December, 2019, an outbreak of a novel coronavirus disease (COVID-19) was reported in Wuhan, China, which has subsequently affected the whole world ${ }^{(1)}$. The pandemic of COVID-19 has clearly entered a new stage with rapid spread in countries outside China and all members of society must understand and practice measures for self-protection and for prevention of transmission of infection to others ${ }^{(2)}$. In general, COVID-19 is an acute resolved disease but it can also be deadly, with a $2 \%$ case fatality rate. Severe disease onset might result in death due to massive alveolar damage and progressive respiratory failure ${ }^{(2,3)}$.

Health care workers are the frontline soldiers against COVID-19 (3), they provide caring for patients during the severe acute respiratory syndrome (SARS) and Middle East respiratory syndrome (MERS) outbreaks were experienced extraordinary stress related to high risk of infection, stigmatization, understaffing, and uncertainty ${ }^{(4,5)}$. An important sector of this army are nurses, they play a very crucial role in predestining the healthcare services for managing and extenuating infectious diseases, as COVID-19, which are considered to be the third leading cause of death worldwide (6). Yet, they face tremendous physical and mental stress as they facing challenges during pandemic, but also, introducing may influential roles $^{(4)}$.

Firstly, one of the most horrific challenge of the COVID-19 is the time delay in the early identification of infections, due to its long incubation period that might extend to about fourteen days on average. This poses a threat to nurses as they considered the initial point of contact with the infected person $(6,7)$. Second challenge is the number of patients that required ventilatory support outnumbered the available intensive care unit (ICU) beds. Moreover the nurse-patient ratio is unbalanced. This put authorities to submit another places as University cities to providing care to those less severity in their signs and symptoms ${ }^{(8)}$.

Third one is to stay healthy so that nurses can continue to care for others. Unfortunately with lack of personal protection equipment (PPE), nurses had to set up a clean area at the entrance to their homes to change in and out of scrubs, besides change and shower at work as well. Unquestionably, they have families, and so will naturally be fearful that the virus might reach those they love most. After then they return their home and isolate themselves from their loving family, another rent a separate house to avoid contact with their families ${ }^{(9)}$.

Lastly, the most tragic and shameful in some communities is harassment, 
stigmatization, and attacking nurses during their work, while they are sacrificing their life and time in giving care to those clients with COVID $-19^{(7,9)}$. Certainly, nurses play a great role in caring the patient during the different phases of the COVID19. Besides, providing public education, to prevent and reduce the spread of misinformation around the disease outbreak. Also, tracing of those around the infected person and guide them to prevent spread of infection ${ }^{(6)}$. Moreover, they have to find a specific balance between professional standards and crisis standards of care which based on the reality of the specific situation, such as the presence or absence of necessary equipment, medications or colleagues ${ }^{(8)}$.

Among nurses, stress has been linked to problems ranging from depression, decreased job satisfaction, and disrupted personal relationships to reduced concentration, impaired decision making, and poorer relationships with patients ${ }^{(10)}$. Accordingly nurses' health and safety are crucial not only for continuous and safe patient care, but also for control of any outbreak. Nurses can experience fear, high level of stress, fatigue, grief and anxiety during facing pandemic. Consequently, through improving the human factor, the nurses could perform at their best while caring for patients ${ }^{(6)}$.
The repeated surge demand from the critically ill patients required the nurse to work with high resilience with a responsible team consisted of medical rescue team, infection control specialists, local health authorities representative, and centre for disease control and prevention $(6,11)$.

Resilience can be promoted by many factors like as optimism, sense of purpose, faith, belief, sense of self, empathy, insight, self-care, hope, self-efficacy, coping, control, flexibility, adaptability and emotional intelligence ${ }^{(7,12)}$. Some particular personal attributes associated with resilience include optimism, intelligence, creativity, a sense of humour, a belief system that provides existential meaning, a range of coping skills, social skills and an appreciation of the uniqueness of self ${ }^{(13)}$. Resilience is experienced when individuals have insight into their ability to recognize stressors and put strategies in place such as humor to minimize the effects. Resilience is enhanced by ensuring exercise, rest, social support and interests are maintained to maximize work- life balance ${ }^{(14)}$.

Hope is the act by which despair is actively overcome. As an inner strength, hope is perceived as a resource for living in the present and is central to a dignified end of lifetime. Besides, hope for nursing is 
identifying as this deep-grounded hope that is most germane to our patients and to our practice ${ }^{(15)}$. Furthermore, inner strength among experienced nurses has been associated with connectedness, firmness, flexibility, creativity, a sense of confidence in oneself yet having faith in others, accepting both the light and the dark side of life, and being the same yet growing into a new garment ${ }^{(16)}$.

In recent decades, meditation has drawn increasing attention as a modality for reducing stress in clinical and general populations. One form of meditation, the Eight-Point Program (EPP), possesses both important similarities to and key differences from other well-known methods of meditation (Easwaran, 1978/1991) as with well-documented work into the remainder of daily living by Kabat-Zinn (2003) and others, the EPP uses a variety of related methods to integrate meditative states of mind, experienced during formal sitting practice (10)

In passage meditation, the object of attention is not an image or an external object but an inspirational passage chosen from any of the world's great spiritual traditions and memorized ahead of time (17). The WHO determine such workplace health programs as one of the best options for mental health and well-being of employees ${ }^{(18)}$. On top of that, development and application of a meditative program that consistent with our culture can be valuable to control and overcome stress, building resilience and hope.

\section{Aim of the study}

To evaluate the effect of passage meditation program on nurses' level of hope and resilience who working with COVID 19 patients.

\section{Research questions:}

What is the effect of passage meditation program on nurses' level of hope and resilience who working with COVID 19 patients?

\section{Research hypothesis:}

1- Directional hypothesis: the passage meditation program would improve level of hope and resilience who working with COVID 19 patients.

2- Null hypothesis: the passage meditation program hasn't any effect on the level of hope and resilience who working with COVID 19 patients.

\section{Subject and method}

Study Design: A quasi-experimental, pre- posttest design was utilized in the current study.

Setting: The study was conducted at Tanta chest hospital affiliated to Ministry of health. It was an online study through using Google forms (Google drive). The respondents fill in an online electronic questionnaire by 
submit the following link https://forms.gle/uCpFZQ9zYm9Nfbw $\mathrm{x} 9$ related to electronic questionnaire.

\section{Subjects:}

All of nurses (fifty nurses) working at Tanta chest hospital.

\section{Tools of the study:}

\section{Tool I: Hearth hope scale:}

It was developed by Kaye Herth 1998 ${ }^{(19)}$. It was intended to measure level of hope. It is a 30-item, 4-point likert scale started with Strongly Disagree = 1, Disagree $=2$, Agree $=3$ and Strongly Agree $=4$. In order to prevent mistakes during answering the scale, note the following items need to be reversed scored: $6,10,13,17,22$, and26.

\section{Tool II: The brief resilience scale (BRS):}

It was developed by Smith et al. (2008) (20). It aimed to assessing individuals' ability to recover from stressful circumstances. It composed of six statements of Items 1, 3, and 5 are positively worded, and items 2, 4, and 6 are negatively worded. The BRS is scored by reverse coding items 2,4 , and 6 and finding the mean of the six items. The items are rated on a five-point Likert Scale 1 = strongly disagree, 2 = disagree, $3=$ neutral, $4=$ agree, $5=$ strongly agree.

* In addition a Socio-demographic and clinical data Questionnaire was used. It was designed by the researchers to elicit data about socio-demographic and clinical characteristics of the studied subjects such as sex, age, residence, level of education, years of experience, knowledge about Covid 19 and provision of personal protection equipment.

\section{Method:}

1-Official permission to conduct the study was obtained from the responsible authorities.

\section{2-Ethical Considerations:}

- Online consent was obtained from nurses after explanation of the aim of the study.

- Privacy and confidentiality was assured. Nurses were reassured that the obtained information is confidential and used only for purpose of the study.

- Nurses' right to withdraw from the study at any phase were respected.

3-All tools were tested for content validity by a jury of five experts in the field of psychiatric nursing.

4-Tools of the study were translated into Arabic language and designed by Google forms to be an online questionnaire.

5-All tools were tested for reliability using Cornbrash's Alpha test and found to be ( $\mathrm{n}=0.785,0.64$ respectively).

6-Online Pilot study was carried out with 10 undergraduate nursing students to evaluate the tentatively tools for the 
clarity, feasibility and the applicability and necessary modifications were done accordingly. Those10 undergraduate nursing students were excluded later from the actual study.

The actual study was divided into four phases:

\section{A-Assessment phase:}

In this phase, a Whats App group were introduced for all nurses and were informed to explain the purpose of the study and to gain their cooperation. The researchers assigns the study tools on the respondents and explains how to fill an online questioner.

\section{B-Planning Phase:}

This phase was formulated based on assessment phase and extensive literature review. Goals and expected outcome criteria were taking into consideration when planning passage meditation program.

The studied nurses were divided into subgroups; each subgroup encompassed 10 nurses. Each subgroup was attending a total of 6 sessions. These sessions were scheduled as 3 sessions per week for duration of 2 weeks. Each session was lasted for about an hour.

The researchers was used the following learning materials:

-Images.

-Videos.

\section{C- Implementing Phase:}

- In this phase, the researchers were meet the study subjects in online bases through Whats App group.

\section{The content of the program was presented} in the following sequences:

\section{-The first session:}

- An introductory session that emphasized establishing rapport between the researchers and the respondents participating in the study and explanation of the purpose of the program.

- The second session: It involves Meditation on a passage which means silent repetition in the mind of memorized inspirational passages from the Holly Quraan and repetition of $a$ HolyWord or Mantram which contains silent repetition in the mind at times other than meditation of a single chosen Holy Name, hallowed phrase or mantram from a major religious tradition which known as Tasbih.

- The third session; includes education about Slowing Down which is an important spiritual discipline. Living faster and faster gives no time for inner reflection or sensitivity to others, making our lives tense, insecure, inefficient, and superficial. Slowing 
down helps to achieve freedom of action, good relations with others, health and vitality, calmness of mind, and the ability to grow. Besides training about Focused/One-pointed Attention through giving full concentration to the matter at hand.

- The fourth session: It composed of Training the Senses which known as overcoming conditioned habits and learning to enjoy what is beneficial and Putting Others First through gaining freedom from selfishness and separateness; finding joy in helping

Others.

- The fifth session: It consists of Spiritual Association through spending time regularly with others following the EPP for mutual inspiration and support Inspirational Reading through reading about great spiritual figures and from religious scriptures as prophet Mohamed.

- The sixth session: Summary of the program and the questionnaires were given to the subjects to submit them as an immediate evaluation of the program.

\section{Statistical analysis:}

The collected data was organized, tabulated, coded and statistically analyzed using the mean, standard deviation standard error, unpaired student t-test, the linear correlation coefficient, Analysis of variance [ANOVA] tests Paired t-test and chi-square by SPSS V19 (Statistical Package for Social Studies) created by IBM, Illinois, Chicago, USA. The level of significance was adopted at $\mathrm{p}<0.05$.

\section{Result}

Table (1): presents the socio-demographic and clinical characteristics of the studied nurses. The results revealed that the majority of nurses were male with age ranging from (30-40 years). In relation to social status about $42 \%$ were single, regarding their educational level, $70 \%$ of them had Bacheloric degree in nursing. In relation to experience year in nursing, the most of them $84.0 \%$ had experience from 1-10 years, and more than half of them have Knowledge about corona. Regarding to ability of them for provision of PPE (personal protective equipment) about $70 \%$ of them have this ability.

Table (2): Show Distribution of The Studied Nurses in Relation to Their Level of Resilience and Hope Pre and Post the Implementation of educational Program. It noted that there is highly statistically significant between nurses resilience score before, and after implementation of the educational program in which (Pvalue $<0.000 *$, this donates that nurses score had improved through the phases of training program. In relation to hope it was founded that $38 \%$ of studied nurses have weak level of hope before program, 
while this level decreased gradually to become $0 \%$ immediately after program .on the other hand, there were about $0 \%$ of studied nurses have high level of hope before program, while this level increased to become $80 \%$ of studied nurses after program.

Table (3): show the mean difference scores of Resilience and hope among studied nurses at pre and post intervention. It Can be noticed a that the Mean score Of resilience Increased from $(9.460 \pm 1.593)$ Pre- intervention to $(15.800 \pm 1.525)$ post intervention with highly statistically significant difference ,Regarding to nurses hope The results revealed that there is highly statistically significant relation between nurses mean score of hope before and post implementation of the training program in which $(\mathrm{P}-$ value $=0.000 *)$.

Table (4): illustrates the correlation between the total score of Resilience and Hope, The results revealed that there is a positive statistically significant relationship between the nurse total resilience score and hope score as P-value $=(0.001) . \quad \mathrm{r}=0.448 * *$.this mean that the better the nurses have high resilience level, the more hope level that nurses provide to covide 19 patients.

Tables (5): reveal correlation between the Total nurses hope Score and Demographic Data for studied sample. It was found that there was non-significant relation between total nurse's hope score and demographic data for studied sample.

Tables (6): reveal relation between the Total nurses resilience Score and Demographic Data for studied sample. It was found that there was non-significant relation between total nurse's resilience score and demographic data for studied sample on other hands it was noticed that there was significant relation between total nurse's resilience score and demographic data for studied sample related to years of experience and provision of PPE (personal protective equipment). 
Table (1): Distribution of Studied Nurses According to Their Socio-Demographic Characteristics

\begin{tabular}{|c|c|c|}
\hline Socio-Demographic Characteristic & $\mathrm{N}$ & $\%$ \\
\hline \multicolumn{3}{|l|}{ Sex } \\
\hline Male & 40 & 80.0 \\
\hline Female & 10 & 20.0 \\
\hline \multicolumn{3}{|l|}{ Age } \\
\hline $20-30$ & 15 & 30.0 \\
\hline $30-40$ & 35 & 70.0 \\
\hline \multicolumn{3}{|l|}{ Education } \\
\hline Bachelor & 35 & 70.0 \\
\hline M.A. & 15 & 30.0 \\
\hline \multicolumn{3}{|l|}{ social status } \\
\hline Single & 42 & 84.0 \\
\hline Married & 8 & 16.0 \\
\hline \multicolumn{3}{|l|}{ years of experience } \\
\hline Less than one year & 4 & 8.0 \\
\hline 1-10 years & 42 & 84.0 \\
\hline More than 10years & 4 & 8.0 \\
\hline \multicolumn{3}{|l|}{ Knowledge about corona } \\
\hline Yes & 26 & 52.0 \\
\hline No & 24 & 48.0 \\
\hline \multicolumn{3}{|l|}{ provision of PPE } \\
\hline Yes & 35 & 70.0 \\
\hline No & 15 & 30.0 \\
\hline
\end{tabular}

Table (2): Distribution of The Studied Nurses in Relation to Their Level of Resilience and Hope Pre and Post the Implementation of educational Program

\begin{tabular}{|c|c|c|c|c|c|c|c|}
\hline \multirow{2}{*}{\multicolumn{2}{|c|}{ Level of Resilience and Hope }} & \multicolumn{2}{|c|}{ Pre } & \multicolumn{2}{|c|}{ Post } & \multicolumn{2}{|c|}{ Chi-square } \\
\hline & & $\mathbf{N}$ & $\%$ & $\mathbf{N}$ & $\%$ & $\mathrm{X}^{2}$ & P-value \\
\hline \multirow{3}{*}{ Resilience } & Week & 37 & 74.0 & $\mathbf{0}$ & 0.0 & \multirow{3}{*}{76.893} & \multirow{3}{*}{$<0.001^{*}$} \\
\hline & Average & 12 & 24.0 & 8 & 16.00 & & \\
\hline & High & 1 & 2.0 & 42 & 84.00 & & \\
\hline \multirow{3}{*}{ Hop } & Week & 19 & 38.00 & 0 & $\mathbf{0}$ & \multirow{3}{*}{69.756} & \multirow{3}{*}{$<0.001 *$} \\
\hline & Average & 31 & 62.00 & 10 & 20.0 & & \\
\hline & High & $\mathbf{0}$ & 0.0 & 40 & 80.0 & & \\
\hline
\end{tabular}


Table (3): Distribution of The Studied Nurses in Relation to Their Total Mean Score of Resilience and Hope Pre and Post the Implementation of educational Program

\begin{tabular}{|c|c|c|c|c|c|c|c|c|}
\hline \multirow{2}{*}{$\begin{array}{c}\text { Phases of } \\
\text { the } \\
\text { program }\end{array}$} & \multicolumn{2}{|c|}{ Pre } & \multicolumn{2}{c|}{ Post } & \multicolumn{2}{c|}{ Difference } & \multicolumn{2}{c|}{ Paired T-test } \\
\cline { 2 - 9 } & Mean & SD & Mean & SD & Mean & SD & t & P-value \\
\hline Resilience & 9.460 & 1.593 & 15.800 & 1.525 & -6.340 & 2.006 & -22.346 & $<0.001^{*}$ \\
\hline Hope & 55.200 & 3.251 & 83.600 & 3.344 & -28.400 & 4.435 & -45.275 & $<0.001 *$ \\
\hline
\end{tabular}

Table (4): Correlation between the Total score of Resilience and Hope

\begin{tabular}{|c|c|c|}
\hline \multicolumn{3}{|c|}{ Correlation between Resilience and Hope } \\
\hline & Pre & Post \\
\hline r & -0.042 & $0.448^{* *}$ \\
\hline P-value & 0.773 & 0.001 \\
\hline
\end{tabular}

Table (5): Relation between the Total nurses hope Score and Demographic Data

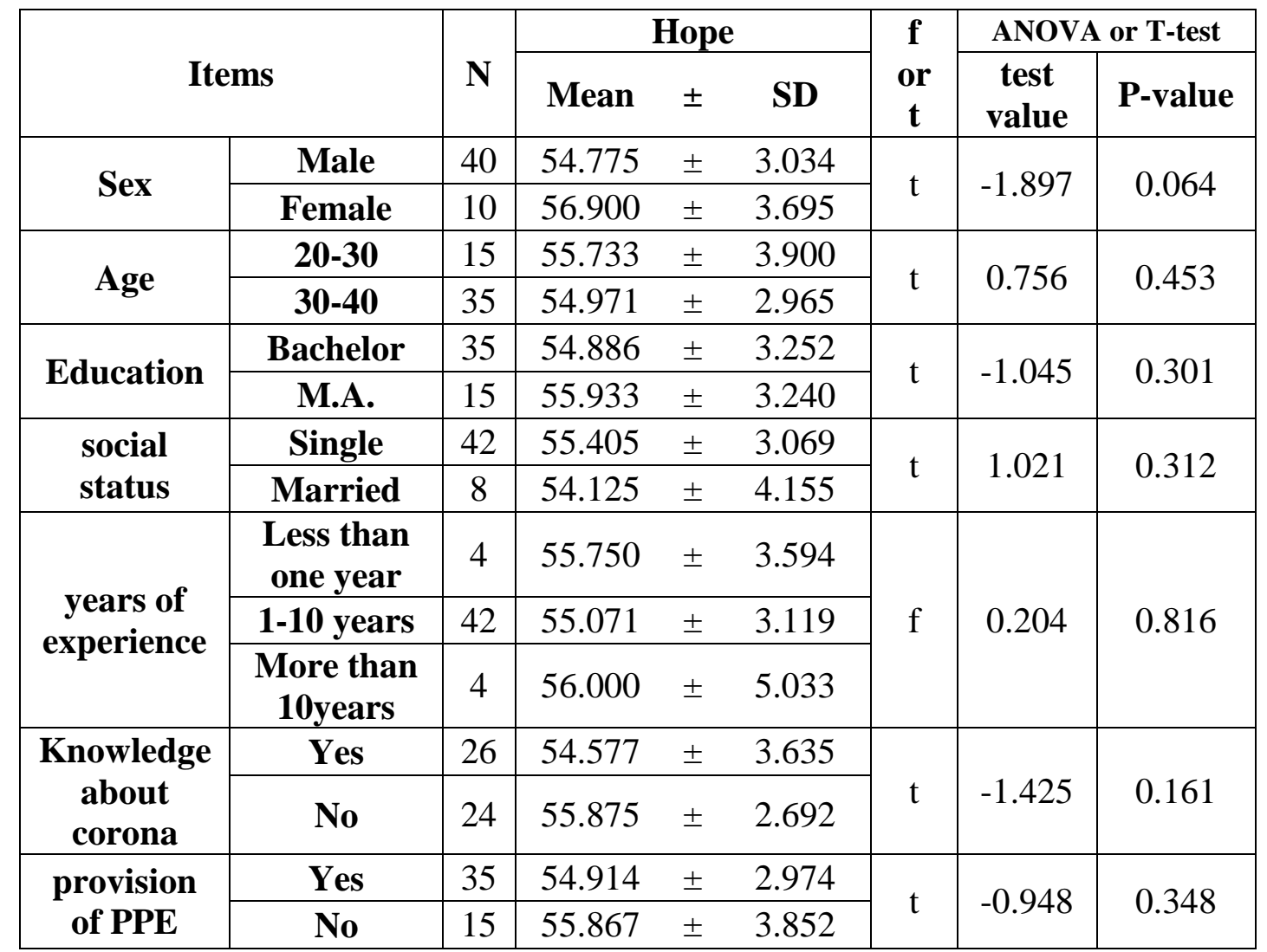


Table (6): Relation between the Total nurses Resilience Score and Demographic Data

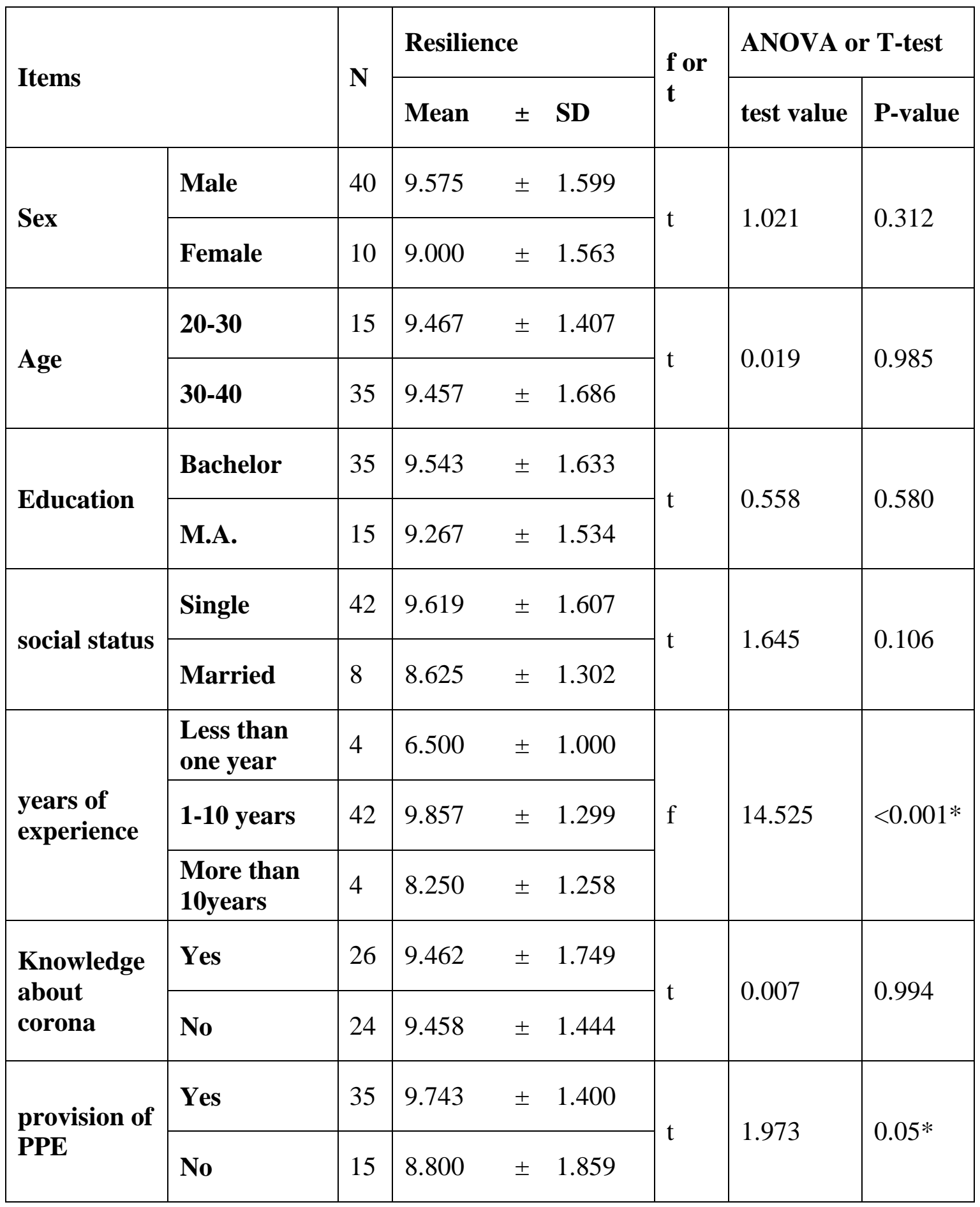




\section{Discussion}

The world is facing the worst public health crisis in recent history. The coronavirus disease (COVID-19) pandemic has directly and indirectly affected more than four million people across the globe, disrupting health systems and economies. It has placed unprecedented pressure on health care worker during providing care for patient with Covide 19, this repeated stress and fear required the nurse to work with high level with hope and resilience in order to provide high qualified nursing care for those patients through following passage meditation program as mentioned before , Alongside with this, the present study conducted to evaluate the effect of passage meditation program on nurses level of hope and resilience who take care of patients with COVID $19^{(21,22)}$.

Emerging result of the present study revealed that the program has positive effect on nurse level of hope and resilience during giving care for patent with covide19 immediately and after implementation of the program. This result may be due to effective developing of the program which contained of six training sessions about passage meditation and mainly based on the studied nurses' needs in addition to its clarity, simplicity, frequent repetition, motivating staff to participate in sessions of the program and also As a result of the way of implementation of program in which researcher used online discussion through WhatsApp group and zoom as a method of teaching and implementing of passage meditation, This enhancement of the nurses also may be due to a magical and psychological impact of passage meditation on raising hope and resilience. This result is supported by Oman (2015) in his study about Passage Meditation Reduces Perceived Stress in Health Professionals, founded that passage meditation has critical effect in reduce health care worker stress In the same stream with this current study Clare et al., (2015) in his study of Understanding individual resilience in the workplace pointed out the resilience of individuals in work place shaped positively after the implementation of program ${ }^{(23,24)}$.

Hope of nurses toward patients with Covide 19 considers the main factor and helpful entrance to improve nurses' resilience score, and on the other hand low level of hope acts as a huge barrier to improve nurses' resilience score. Consistent with this point, the present study indicated that there is a positive statistically significant relationship between the nurse total resilience score and hope score. This mean that the better the nurses have high resilience level, the more hope level that nurses provide to 
Covide 19 patients. This result matched with Gito (2013) in his study of The relationship of resilience, hardiness, depression and burnout among Japanese psychiatric hospital nurses, proved that there are negative correlation between nurse hardness, depression and resilience $^{(25)}$.

Finally, it is worth to mention that there was non-significant relation between total nurse's hope score and demographic data for studied sample. This result mean that there aren't any effect of demographic data on enhancement of nurses hope score this refer to high success rate of this program as researcher use simple language during implementation of program that was suitable to all educational level, and cover wide range of knowledge about passage meditation, in contrary to this study Stavarski et al., (2018) in his study of exploring nurses' and patients' perceptions of hope and hope-engendering nurse interventions in an eating disorder facility founded that female nurses had significantly higher hope scores compared to males ${ }^{(26)}$.

Similarly to what mention in previous result. It was found that there was a negative and non-significant correlation between nurses resilience score and demographic data also there was a positive relationship pre, post program regarding their total resilience score and years of experience, where the more years of experience, the more level of resilience toward those patients. This can be explained that years of experience of nurse plays a significant part in care and can impact the nurses' level resilience toward those patients when compared with nurse who have low experience, in the same streem, general Gito et al., (2013) proposed that years of experience consider favorable starting point in developing nurse resilience ${ }^{(25)}$.

In addition to what mention before there was a positive relationship pre, post program regarding their total resilience score and provision of protective equipment, this mean that nurse who has ability to use all protective equipment all time during contact with those highly infected patients, keep nurse more flexible and have high level of resilience during giving care to this patients than other nurse who can't use this protective equipment. This result was in keeping with Zhang et al., (2020) in their research of protecting healthcare personnel from corona virus infection risks ${ }^{(27)}$.

\section{Conclusion}

Based on the results of the current study, it can be concluded that the passage meditation program was effective in elevation hope level and improving resilience among nurses. 


\section{Recommendation}

Based on the findings of the current study the following recommendation was suggested:

1- Nurses should be involved in the details of the national plan for high preparedness.

2- The global nursing organizations work on drafting effective and proactive nurses' human-factor guidelines and network that embeds human factor as a dynamic shock absorber.

3- The role of the psychiatric nursing and mental health department should not be ignored, because they can have a valuable role in reducing the stress and helping nurses in hard times.

\section{References}

1. $\mathrm{Xu} \mathrm{Z}$, Shi L, Wang Y, Zhang J, Huang L, Zhang C, et al. Pathological findings of COVID-19 associated with acute respiratory distress syndrome. Lancet respiratory Journal. 2020; 8(1): 420-22. https://doi.org/10.1016/ S2213-2600(20)30076-X.

2. Zhou F, Yu T, Du R .Clinical course and risk factors for mortality of

3. adult inpatients with COVID-19 in Wuhan, China: A retrospective cohort

4. study. Lancet journal. 2020. Available from: https://doi.org/ 10.1016/S01406736(20)30566-3.

5. Chatterjee S, Kagwe M. Health workers are the frontline soldiers against COVID-19. Let's protect them. March 2020. https://www.un. org/africarenewal/web-features/ coronavirus/health-workers-arefrontline-soldiers-against-covid-19let $\% \mathrm{E} 2 \% 80 \% 99$ s-protect-them.

6. Spinelli $\mathrm{Ch}$, Wisener M, Khoury B. Mindfulness training for healthcare professionals and trainees: A metaanalysis of randomized controlled trials. Journal of Psychosomatic Research. 2019; 123(1): 109 . DOI: 10.1016/j.jpsychores.2019.03.003

7. Liu Q, Luo D, Haase J, Guo Q, Wang $\mathrm{X}$, Liu S. The experiences of healthcare providers during the COVID-19 crisis in China: A qualitative study. Lancet Glob Health Journal. 2020; 8(1): e790- e798. DOI: https://doi.org /10.1016/S2214-109X(20)30204-7

8. Buheji M, Buhaid N. Nursing human factor during COVID-19 Pandemic. International Journal of Nursing Science. 2020; 10(1): 12-24. DOI: 10.5923/j.nursing. 20201001.02

9. Lachant A, Madarasz G. International Nurses Day: Nurses Deserve Praise, Thanks, Protection Amid COVID-19. May 2020. https://www.icn.ch/news/internationalnurses-day-nurses-deserve-praisethanks-protection-amid-covid-19.

10. Juana $Y$, Yuanyuana C, Qiuxianga Y, Conga L, Xiaofengb L, Yundonga 
$\mathrm{Z}$, et al. Psychological distress surveillance and related impact analysis of hospital staff during the COVID-19 epidemic in Chongqing, China. Comprehensive Psychiatry. 2020.: https://doi.org/

10.1016/j.comppsych.2020.152198

11. Chevancea A, Gourionb D, Hoertelc N, Llorcad P, Thomase P, Bocherf R, et al. Ensuring mental health care during the SARS-CoV-2 epidemic in France: A narrative review. L'Encéphale Journal. 2020; 46(1): 193-201.:

https://doi.org/10.1016/j.encep.2020. 04.005 .

12. 10Oman D, Hedberg J, Thoresen C. Passage meditation improves caregiving self-efficacy among health professionals a Randomized Trial and Qualitative Assessment. Journal of Health Psychology. 2008; 13(8) 1119-1135. DOI: $10.1177 / 1359105308095966$

13. American Nurses Association. Nurses Responding to Global Pandemics. 2020.: https:// onlinenursing.duq.edu/blog/nursesresponding-to-global-pandemics/. Accessedon:1/4/2020.

14. Delgado $\mathrm{C}$, Upton $\mathrm{D}$, Ranse $\mathrm{K}$, Furness T. Nurses' resilience and the emotional labor of nursing work: An integrative review of empirical literature. International Journal of Nursing Studies. 2017; 70(1): 7188.: $\quad$ http://dx.doi.org /10.1016/j.ijnurstu.2017.02.008.

15. Foureur M, Besley k, Burton G, Yu N, Crisp J. Enhancing the resilience of nurses and midwives: Pilot of a mindfulness based program for increased health, sense of coherence and decreased depression, anxiety and stress. Contemporary Nurse. 2013; 45(1): 114-125. DOI: 10.5172/ conu.2013.45.1.114 Source: PubMed

16. Cross W. Building resilience in nurses: The need for a multiple pronged approach. Journal of Nursing and Care. 2015; 4 (2): 124126. DOI: $10.4172 / 2167-$ $1168.1000 \mathrm{e} 124$.

17. Paquette K. Perspectives on Hope of Hospice and Palliative Care Nurses. : https://digitalcommons.

uri.edu/cgi/viewcontent.cgi?article $=1$ $413 \&$ context $=$ oa_diss.

18. Haugan G, Espnes G. Nurse-patient interaction: A resource for hope in cognitively intact nursing home patients. Journal of Holistic Nursing. 2013; 31(3): 152-163.

19. Nagler M. Try Passage meditation with spiritual texts. Yoga journal. 2017.: https://www.yogajournal. com/yoga-101/words-of-inspiration. 
20. Lynch J, Prihodova L, Dunne P, O’Leary C, Breen R, Carroll A, et al. Mantra meditation programme for emergency department staff: A qualitative study. BM Journal. 2018; 8(1): $\quad$ e020685. Doi: 10.1136/bmjopen-2017-020685.

21. Herth, K. Hope as seen through the eyes of homeless children. Journal of Advanced Nursing. 1998; 28(5): 1053-1062. Doi:10.1046/j.13652648.1998.00813.x.

22. Smith B, Dalen J, Wiggins K, Tooley E, Christopher P, Bernard J. The brief resilience scale: Assessing the ability to Bounce Back. International Journal of Behavioral Medicine. 2008: 15(1): 194-200. DOI: 10.1080/ 10705500802222972.

23. World Health Organization. Coronavirus Disease 2019 (COVID19) Situation Report - 111. 2020.: https://www.who.int/ docs/defaultsource/coronaviruse/situ ation-reports/20200510covid-19sitrep-111.pdf?sfvrsn=1896976f_2.

24. Salajan A, Tsolova S, Ciotti M, Suk JE. To what extent does evidence support decision making during infectious disease outbreaks? A scoping literature review. Evid Policy. 2020.: 10.1332/174426420X 15808913064302.
25. Doug O, Passage Meditation Reduces Perceived Stress in Health Professionals. Journal of Consulting and Clinical Psychology. 2015; 74(4): 714-719. Copyright 2015by the American Psychological Association 2006.

26. Clare S, Lauren J. Breen1, Lynette Cusack2, Desley H. The relationship of resilience, hardiness, depression and burnout among Japanese psychiatric hospital nurses Front. Psychol. 2015.: https://doi.org/ 10.3389/ fpsyg.2015.0007

27. Gito M, Hiroyuki Ogata1 Journal of Nursing Education and Practice: 2013:3(11) DOI: 10.5430/ jnep.v3n11p12 URL: http://dx.doi. org/10.5430/jnep.v3n11p1

28. Stavarski R, Debra H. Exploring nurses' and patients' perceptions of hope and hope-engendering nurse interventions in an eating disorder facility. Journal of Psychiatric and Mental Health Nursing. 2018; 26(1):1-2.:https:// doi.org/10.1111/jpm.12507

29. Zhang Z, Liu S, Xiang M, Protectin $\mathrm{g}$ healthcare personnel from $\mathrm{CoV}$ infection risks: Lessons and suggestions. Front Med. 2020; 14(1): 229-31. 